\title{
A non-interventional cross-sectional re- contact study investigating the relationship between overactive bladder and frailty in older adults in Japan
}

\author{
Masaki Yoshida', Shosuke Satake ${ }^{2}$, Kota Ishida ${ }^{3}$, Yusuke Tanaka ${ }^{4}$ and Masashi Ukai ${ }^{3^{*}}$ (1)
}

\begin{abstract}
Background: Increasing age is associated with frailty and a higher prevalence of overactive bladder (OAB). Given the rapidly increasing proportion of older adults in Japan, a better understanding of the relationship between frailty and $O A B$ is needed to inform future healthcare planning. This study assessed the association between frailty and $O A B$ in older adults in Japan and evaluated the impact on their health-related quality of life (HRQoL).

Methods: This was a cross-sectional re-contact study of respondents who previously completed the National Health and Wellness Survey 2018 in Japan. Participants were aged $\geq 65$ years and Japanese speakers and readers. As part of a customized online survey, participants were screened for frailty using the Kihon Checklist (frail =scores $\geq 8$ points) and $O A B$ using the overactive bladder symptom score $(O A B=$ total score $\geq 3$ points and $\geq 2$ points on question 3$)$. The primary endpoint was the odds ratio of frailty in older adults with and without $O A B$ assessed using a multivariable logistic regression model. Secondary endpoints were the prevalence rates of $O A B$ and frailty. Exploratory endpoints assessed HRQoL using the Medical Outcomes Study 12-Item Short Form Survey Instrument version 2 (SF-12v2).

Results: Overall, 2953 participants were included: 150 (5.1\%) were frail OAB, 416 (14.1\%) non-frail OAB, 287 (9.7\%) frail non- $O A B$, and 2100 (71.1\%) non-frail non-OAB. There was a statistically significant correlation between frailty and $O A B$ demonstrated by an adjusted odds ratio $(95 \% \mathrm{Cl})$ of $2.78(2.18-3.54 ; p<0.001)$. The prevalence $(95 \% \mathrm{Cl})$ of OAB was $34.3 \%$ (29.9-38.8) in frail and 16.5\% (15.1-18.0) in non-frail older adults; the prevalence of frailty was 26.5\% (22.9-30.1) and $12.0 \%(10.7-13.3)$ in older adults with and without OAB. HRQoL was assessed in 150 participants per group. The adjusted HRQoL analyses showed significantly lower scores in participants who were frail $O A B$ vs. frail non-OAB for most of the SF-12v2 scores/sub-component scores.
\end{abstract}

Conclusions: These data highlight the statistically significant positive correlation between frailty and $O A B$ among older adults in Japan and may provide valuable information on the burden of $O A B$ and frailty on older adults to healthcare professionals when considering future healthcare planning.

Keywords: Overactive bladder, Frailty, Older adults, Japan

*Correspondence: masashi.ukai@astellas.com

${ }^{3}$ Medical Affairs, Astellas Pharma Inc., Tokyo, Japan

Full list of author information is available at the end of the article

\section{Background}

Worldwide, Japan has the highest percentage of its population that is at least 65 years of age (28.7\%) [1]. The majority of this age group are women and there are $\sim 80,000$ individuals who are at least 100 years old. 
Residents of Japan have a high life expectancy and the government is acting to address the consequences of an aging population, including adequate healthcare provision [1].

Increasing age is associated with increasing frailty, defined as a multifactorial geriatric syndrome characterized by age-associated reductions in physiologic reserve and function across multi-organ systems [2]. The prevalence of frailty in Japan in those aged 65 years or older has been estimated at between 7.4 and $21.6 \%[3,4]$ and frailty is associated with a high risk of morbidity and mortality [2].

Overactive bladder $(\mathrm{OAB})$ syndrome is defined as "urinary urgency, usually accompanied by increased daytime frequency and/or nocturia, with urinary incontinence (OAB-wet) or without (OAB-dry), in the absence of urinary tract infection or other detectable disease" [5]. The prevalence of $\mathrm{OAB}$ in Japan is $\sim 12.4 \%$ among adults aged $\geq 40$ years and increases with age from $5 \%$ in those aged $40-49$ to $37 \%$ in those aged 80 years or over [6, 7]. OAB can place a significant burden on individuals, in terms of adversely affecting their quality of life, mood (anxiety and depression), and daily activities and also has an impact on healthcare costs [8-11].

Although an association between frailty and $O A B$ has been demonstrated in non-Japanese populations [12], a better understanding of the relationship is needed to inform future healthcare planning given the rapidly increasing proportion of older adults in the Japanese population. Hence, the objectives of this study were to assess the association between frailty and $O A B$ in older adults in Japan and to evaluate the impact on their health-related quality of life (HRQoL).

\section{Methods}

\section{Study design and endpoints}

This was a cross-sectional re-contact study of respondents who had previously completed the National Health and Wellness Survey (NHWS) 2018 in Japan [13]. The NHWS is a cross-sectional survey conducted worldwide (Japan, USA, France, Germany, Italy, Spain, UK, China, South Korea, Taiwan, Russia, and Brazil). In Japan, the NHWS is a self-administered, internet-based questionnaire that is completed by respondents aged at least 18 years who are members of the Kantar Profiles global panel or its panel partners, which are general purpose, web-based opt-in consumer panels. However, the demographic data provided can be used for healthcare purposes [13]. A stratified random sampling procedure was implemented to ensure that the demographic composition of the NHWS sample was representative of the adult population in Japan in terms of sex and age. Approval for this study was provided by a Central IRB (Pearl IRB, Indianapolis, IN, USA).

The primary endpoint of the study was the odds ratio of frailty in older adults with $\mathrm{OAB}$ to that of frailty in older adults without OAB. Secondary endpoints were the prevalence of older adults with $\mathrm{OAB}$ in the frail vs. non-frail groups, and the prevalence of older adults who are frail with $\mathrm{OAB}$ vs. without $\mathrm{OAB}$. Exploratory endpoints were the Medical Outcomes Study 12-Item Short Form Survey Instrument version 2 (SF-12v2 ${ }^{\mathrm{TM}}$, standard version) [14] Japanese norm-based Physical Component Summary (PCS), Mental Component Summary (MCS), Role Component Summary (RCS), and 6-dimensional health state classification (SF-6D) score, and scores for the eight SF12v2 health domains.

\section{Participants and assessments}

Participants were included if they were 65 years or older, speak and read Japanese, and provided informed consent to participate. Participants who required long-term care or support from the Japanese Ministry of Health, Labor and Welfare (MHLW) were excluded. Participants could withdraw from the study for any reason, at any time, without giving a reason for doing so and without penalty or prejudice, and anyone who withdrew consent for their data to be used in the study was discontinued.

As part of a customized online survey, participants were screened for frailty using the Kihon Checklist [15] and for $\mathrm{OAB}$ using the overactive bladder symptom score (OABSS) [16] (Fig. 1). The Kihon Checklist was developed by the Japanese MHLW to assess frailty in older adults and initiate appropriate care needs. There are 25 questions regarding physical strength, nutrition, eating, socialization, memory, mood, and lifestyle which are answered yes/no and scored 0 (pass) or 1 (fail). The maximum score of 25 indicates severe frailty, and in this study frailty was defined as a score of $\geq 8$ points [15]. The OABSS is a tool for assessing OAB symptoms. The sum score is obtained from the responses to four questions regarding the frequency of daytime voiding, nighttime voiding, urgency, and urgency incontinence, with a maximum score of 15 [16]. Participants were classified as having $O A B$ if they had a total of $\geq 3$ points on the OABSS and $\geq 2$ points on question 3 of the OABSS. Four subgroups were established based on the responses: frail $O A B$, non-frail $O A B$, frail non- $O A B$, and non-frail nonOAB. These participants comprised population 1. Data collection was completed when each of the four subgroups reached at least the target sample size $(N=150)$. The target sample size was determined to provide $80 \%$ power to detect an effect size of 0.325 for HRQoL scores between frail $\mathrm{OAB}$ and frail non-OAB using a two-tailed $t$-test at the $5 \%$ significance level. Conventionally, an 


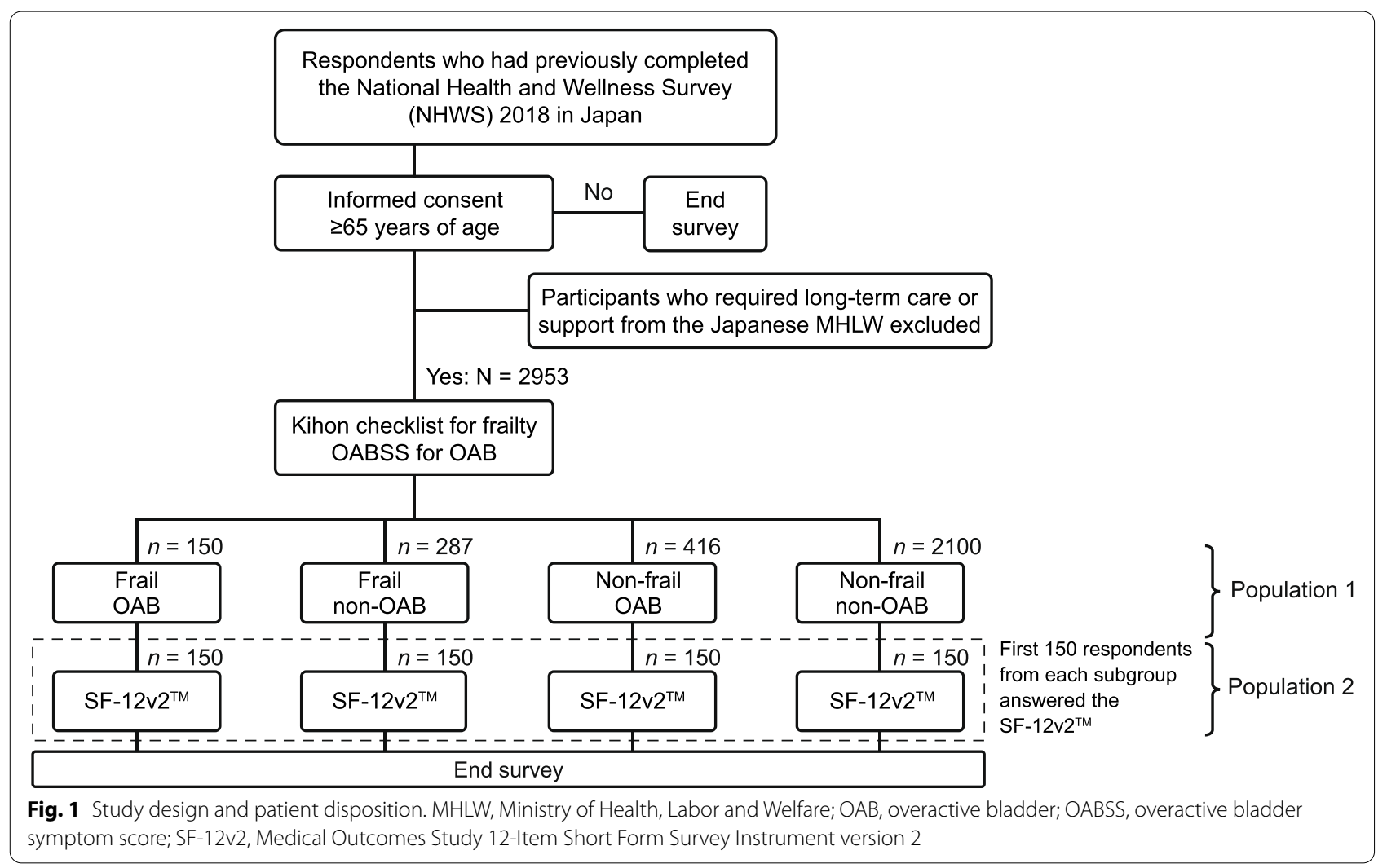

effect size of 0.2 is considered small, 0.5 is considered medium, and 0.8 is considered large. Hence this target sample size was able to detect a small to medium effect size.

The SF-12v2 is a validated scale for assessing HRQoL. This questionnaire uses eight health domains summarized into three scores (PCS, MCS, and RCS) for the Japanese population using the Japanese norm-based scoring. The SF-12v2 is also used to generate health state utilities by applying the SF-6D algorithm [14, 17-19]. Participants were invited to complete the SF-12v2 [14] on a sequential basis until HRQoL data had been collected from the target sample size of 150 for each subgroup (Fig. 1). These participants comprised population 2.

Sociodemographic (age, sex, education, annual household income, living status), clinical characteristics (Charlson comorbidity index [non-age adjusted version [20]]), and lifestyle information (smoking status, alcohol use, exercise behavior) were extracted from the 2018 NHWS Japan database and combined with data from the customized survey by matching the respondents' panel IDs.

\section{Statistical analyses}

For the demographic and clinical characteristics, continuous variables were summarized as the mean and standard deviation (SD) and categorical variables as the frequency (percentage).

For the primary endpoint, a crude odds ratio was calculated and the Chi-square test applied at the level of significance of 0.05 . A multivariable logistic regression model with frailty status as the dependent variable and $\mathrm{OAB}$ status as the independent variable was then used to generate odds ratios $(95 \% \mathrm{CI})$ for the relationship between $\mathrm{OAB}$ and frailty. Backward elimination was used to determine which variables remained in the final model $(p<0.15$ to retain), while prespecified variables of clinical importance (age, sex, living status, Charlson comorbidity index, exercise behavior) were retained regardless of the $p$-value. The prespecified variables of clinical importance were determined following discussions with medical experts in the fields of urology and geriatrics and were based on their latest knowledge and experiences.

The prevalence of $\mathrm{OAB}$ in frail and non-frail older adults was estimated as the number who had $O A B$ divided by the number in the frail and non-frail groups, respectively. Similarly, the prevalence of frailty in older adults with $\mathrm{OAB}$ and without $\mathrm{OAB}$ was estimated as the number who were frail divided by the number who had $\mathrm{OAB}$ and who did not have $\mathrm{OAB}$, respectively.

For the exploratory endpoint (HRQoL), mean and SD were used to summarize the data. One-way ANOVA 
weighted with a sampling ratio from population 1 to population 2 was used to assess differences in HRQoL. In addition, among frail older participants, generalized linear models with normal distributions and identity link function and weighted with the sampling ratio were used, with HRQoL as the dependent variable and OAB status as the independent variable. Like the method used for the primary analysis, the variables included in the final model were selected using backward elimination, with SF-6D as the dependent variable.

An additional analysis was undertaken to assess the association between frailty status and OAB severity. For frailty, robust was defined as a Kihon Checklist total score of $0-3$ and pre-frail as a total score of 4-7. Severe/ moderate $\mathrm{OAB}$ was defined as a total OABSS of $\geq 6$ and mild $\mathrm{OAB}$ as a total $\mathrm{OABSS} \leq 5$.

\section{Results}

A total of 2953 participants gave consent to be included in the study. Of these, 437 were classed as frail and 2516 as non-frail, while 566 had $\mathrm{OAB}$ and 2387 were non$\mathrm{OAB}$; the numbers in each subgroup were frail $\mathrm{OAB}$, $n=150$; non-frail OAB, $n=416$; frail non-OAB, $n=287$; and non-frail non-OAB, $n=2100$ (population 1). As per the study design, there were 150 participants in each of the four subgroups in population 2 (Fig. 1). The demographic and clinical characteristics of the overall populations and subgroups are shown in Table 1 . In the overall group the majority were male $(65.0 \%)$, were married/living with a partner $(81.4 \%)$, and had a university degree (58.6\%). Further details of OABSS scores and severity are given in Supplementary Table 1, Additional File 1.

Analysis of the primary endpoint found a statistically significant correlation between frailty status and $O A B$ status in this population of older adults $(p<0.001) ; 5.1 \%$ were frail $O A B, 9.7 \%$ were frail non-OAB, $14.1 \%$ were non-frail $\mathrm{OAB}$, and $71.1 \%$ were non-frail non-OAB. The crude odds ratio $(95 \% \mathrm{CI})$ was $2.64(2.11-3.30)$. Using logistic regression (frailty status dependent variable; $\mathrm{OAB}$ status independent variable) and adjusting for age, sex, level of education, household income, living status, Charlson comorbidity index, body mass index, smoking status, use of alcohol, and exercise behavior, the odds ratio was $2.78(2.18-3.54 ; p<0.001$; Table 2$)$.

The overall prevalence $(95 \% \mathrm{CI}$ ) of OAB was $19.2 \%$ (17.7-20.6) and the prevalence of frailty was $14.8 \%$ (13.516.1). The prevalence estimates by group are shown in Fig. 2. The unadjusted analyses of HRQoL data in population 2 showed significantly lower scores in participants who were frail $O A B$ compared with non-frail $O A B$ across all scores and all sub-component scores (Fig. 3). Analyses adjusted for age, sex, household income, living status, Charlson comorbidity index, body mass index, and exercise behavior also showed that those who were frail OAB had significantly lower HRQoL scores than those who were frail non-OAB, with the exceptions of MCS, general health, and vitality (Supplementary Fig. 1, Additional File 2). Analysis of an association between frailty status and $O A B$ severity suggested that the prevalence of frailty tends to increase in accordance with the severity of OAB (Fig. 4).

\section{Discussion}

This study demonstrated a statistically significant correlation between frailty and $\mathrm{OAB}$ in older adults in Japan; logistic regression suggested that older adults with $\mathrm{OAB}$ were 2.78 times more likely to be frail than those without $\mathrm{OAB}$. The prevalence of $\mathrm{OAB}$ was also higher among the frail (34.3\%) compared with the non-frail group (16.5\%). Similarly, the prevalence of frailty was higher among older adults with OAB (26.5\%) compared with those without OAB (12.0\%). Finally, there were significant differences in HRQoL between older adults with OAB who were frail and non-frail, and between older adults who were frail with and without $O A B$.

Pelvic floor weakness is one of the factors associated with $\mathrm{OAB}[21,22]$. Therefore, $\mathrm{OAB}$ may have a shared pathophysiology with frailty (especially, physical frailty). Previous studies have investigated an association between frailty and $O A B$, although the Timed Up and Go Test (TUGT) was used instead of the Kihon Checklist. The TUGT measures the time taken to get up from a chair, walk $3 \mathrm{~m}$, turn, return, and sit down again. While it cannot assess all aspects of frailty, it has been shown to distinguish between frail and non-/pre-frail populations [23]. The method used to assess OAB also differed between studies; we used the OABSS, while other measures were the International Consultation on Incontinence female lower urinary tract symptoms questionnaire [24], medication dispensation records or self-reporting [25], and use of ICD codes [12, 25]. A prospective study in the United States found that individuals with $\mathrm{OAB}$ had slower TUGT results than those without OAB, and 32.3\% of individuals with $\mathrm{OAB}$ were categorized as slow/frail compared with $11.0 \%$ without OAB [12]. A second prospective study of women receiving home care in Canada also reported a significant correlation between TUGT score and $\mathrm{OAB}$ at baseline and 3 months, with TUGT score also indicating fall risk [24]. Although not specifically categorized as being about frailty, a systematic review of falls and fractures associated with $O A B$ found that 11.3 to $56.0 \%$ of patients with $\mathrm{OAB}$ experienced recurrent or serious falls and, when comparison with a non-OAB cohort was possible, there was a 1.3- to 2.3-fold increase in the risk of falls for OAB vs. non-OAB [25]. 
Table 1 Demographic characteristics

\begin{tabular}{|c|c|c|c|c|c|}
\hline \multirow[t]{2}{*}{ Population 1} & \multirow[t]{2}{*}{ Total $(N=2953)$} & \multicolumn{2}{|l|}{$\mathrm{OAB}(n=566)$} & \multicolumn{2}{|l|}{ Non-OAB $(n=2387)$} \\
\hline & & Frail $(n=150)$ & Non-frail $(n=416)$ & Frail $(n=287)$ & Non-frail $(n=2100)$ \\
\hline Mean (SD) age, years & $71.7(4.2)$ & $71.5(4.6)$ & $72.7(4.4)$ & $71.4(4.1)$ & $71.6(4.1)$ \\
\hline \multicolumn{6}{|l|}{ Sex } \\
\hline Male & $1919(65.0)$ & $110(73.3)$ & $330(79.3)$ & $192(66.9)$ & $1287(61.3)$ \\
\hline Female & $1034(35.0)$ & $40(26.7)$ & $86(20.7)$ & $95(33.1)$ & $813(38.7)$ \\
\hline \multicolumn{6}{|l|}{ Relationship status } \\
\hline Married/living with partner & $2403(81.4)$ & $111(74.0)$ & $363(87.3)$ & $228(79.4)$ & $1701(81.0)$ \\
\hline $\begin{array}{l}\text { Single/divorced/separated/widowed/ } \\
\text { declined to answer }\end{array}$ & $550(18.6)$ & $39(26.0)$ & $53(12.7)$ & $59(20.6)$ & $399(19.0)$ \\
\hline \multicolumn{6}{|l|}{ Education } \\
\hline University degree & $1729(58.6)$ & $77(51.3)$ & $287(69.0)$ & $142(49.5)$ & $1223(58.2)$ \\
\hline No/declined to answer & $1224(41.4)$ & $73(48.7)$ & $129(31.0)$ & $145(50.5)$ & $877(41.8)$ \\
\hline \multicolumn{6}{|l|}{ Household income } \\
\hline$<¥ 3,000,000$ & $642(21.7)$ & $40(26.7)$ & $77(18.5)$ & $83(28.9)$ & $442(21.0)$ \\
\hline$¥ 3,000,000$ to $<¥ 5,000,000$ & $982(33.3)$ & $50(33.3)$ & $150(36.1)$ & $89(31.0)$ & $693(33.0)$ \\
\hline$¥ 5,000,000$ to $<¥ 8,000,000$ & $603(20.4)$ & $29(19.3)$ & $98(23.6)$ & $42(14.6)$ & $434(20.7)$ \\
\hline$¥ 8,000,000$ or more & $342(11.6)$ & $8(5.3)$ & $58(13.9)$ & $29(10.1)$ & $247(11.8)$ \\
\hline Declined to answer & $384(13.0)$ & $23(15.3)$ & $33(7.9)$ & $44(15.3)$ & $284(13.5)$ \\
\hline \multicolumn{6}{|l|}{ Living status } \\
\hline Live alone (NHWS) & $386(13.1)$ & $24(16.0)$ & $35(8.4)$ & $38(13.2)$ & $289(13.8)$ \\
\hline Live with someone (NHWS) & $2567(86.9)$ & $126(84.0)$ & $381(91.6)$ & $249(86.8)$ & $1811(86.2)$ \\
\hline Mean (SD) Charlson comorbidity index & $0.28(0.60)$ & $0.47(0.78)$ & $0.31(0.62)$ & $0.40(0.74)$ & $0.24(0.55)$ \\
\hline \multicolumn{6}{|l|}{ BMI } \\
\hline$<18.5$ & $214(7.2)$ & $11(7.3)$ & $18(4.3)$ & $33(11.5)$ & $152(7.2)$ \\
\hline$\geq 18.5-<23$ & $1497(50.7)$ & $54(36.0)$ & $203(48.8)$ & $117(40.8)$ & $1123(53.5)$ \\
\hline$\geq 23-<25$ & 707 (23.9) & $36(24.0)$ & $115(27.6)$ & $59(20.6)$ & $497(23.7)$ \\
\hline$>25$ & $535(18.1)$ & $49(32.7)$ & $80(19.2)$ & $78(27.2)$ & $328(15.6)$ \\
\hline \multicolumn{6}{|l|}{ Parkinson's disease } \\
\hline Not experienced & $2951(99.9)$ & $149(99.3)$ & $416(100)$ & $287(100)$ & $2099(100)$ \\
\hline Experienced & $2(0.1)$ & $1(0.7)$ & 0 & 0 & $1(0.0)$ \\
\hline \multicolumn{6}{|l|}{ Falls } \\
\hline No fall in the last year & $2181(73.9)$ & $80(53.3)$ & $302(72.6)$ & $154(53.7)$ & $1645(78.3)$ \\
\hline Fall in the last year & $772(26.1)$ & $70(46.7)$ & $114(27.4)$ & $133(46.3)$ & $455(21.7)$ \\
\hline \multicolumn{6}{|l|}{ Smoking status } \\
\hline Never & $1400(47.4)$ & $55(36.7)$ & $167(40.1)$ & $118(41.1)$ & $1060(50.5)$ \\
\hline Former & $1068(36.2)$ & $63(42.0)$ & $189(45.4)$ & $101(35.2)$ & $715(34.0)$ \\
\hline Current & $485(16.4)$ & $32(21.3)$ & $60(14.4)$ & $68(23.7)$ & $325(15.5)$ \\
\hline \multicolumn{6}{|l|}{ Use of alcohol } \\
\hline Abstain & $861(29.2)$ & $46(30.7)$ & $105(25.2)$ & $99(34.5)$ & $611(29.1)$ \\
\hline Currently consume & $2092(70.8)$ & $104(69.3)$ & $311(74.8)$ & $188(65.5)$ & $1489(70.9)$ \\
\hline \multicolumn{6}{|l|}{ Vigorous exercise in past 30 days } \\
\hline No & $1335(45.2)$ & $91(60.7)$ & $161(38.7)$ & $179(62.4)$ & $904(43.0)$ \\
\hline Yes & $1618(54.8)$ & $59(39.3)$ & $255(61.3)$ & $108(37.6)$ & $1196(57.0)$ \\
\hline \multirow[t]{2}{*}{ Population 2} & Total $(n=600)$ & $\mathrm{OAB}(n=300)$ & & Non-OAB $(n=300)$ & \\
\hline & & Frail $(n=150)$ & Non-frail $(n=150)$ & Frail $(n=150)$ & Non-frail $(n=150)$ \\
\hline Mean (SD) age, years & $71.5(4.4)$ & $71.5(4.6)$ & $72.2(4.5)$ & $71.3(4.4)$ & $71.0(4.1)$ \\
\hline \multicolumn{6}{|l|}{ Sex } \\
\hline Male & $481(80.2)$ & $110(73.3)$ & $138(92.0)$ & $119(79.3)$ & $114(76.0)$ \\
\hline Female & $119(19.8)$ & $40(26.7)$ & $12(8.0)$ & $31(20.7)$ & $36(24.0)$ \\
\hline
\end{tabular}


Table 1 (continued)

\begin{tabular}{|c|c|c|c|c|c|}
\hline \multicolumn{6}{|l|}{ Relationship status } \\
\hline Married/living with partner & $479(79.8)$ & $111(74.0)$ & $126(84.0)$ & $121(80.7)$ & $121(80.7)$ \\
\hline $\begin{array}{l}\text { Single/divorced/separated/widowed/ } \\
\text { declined to answer }\end{array}$ & $121(20.2)$ & $39(26.0)$ & $24(16.0)$ & $29(19.3)$ & $29(19.3)$ \\
\hline \multicolumn{6}{|l|}{ Level of education } \\
\hline University degree & $368(61.3)$ & $77(51.3)$ & $111(74.0)$ & $79(52.7)$ & $101(67.3)$ \\
\hline No/declined to answer & $232(38.7)$ & $73(48.7)$ & $39(26.0)$ & $71(47.3)$ & $49(32.7)$ \\
\hline \multicolumn{6}{|l|}{ Household income } \\
\hline$<¥ 3,000,000$ & $141(23.5)$ & $40(26.7)$ & $27(18.0)$ & $44(29.3)$ & $30(20.0)$ \\
\hline$¥ 3,000,000$ to $<¥ 5,000,000$ & $205(34.2)$ & $50(33.3)$ & $49(32.7)$ & $50(33.3)$ & $56(37.3)$ \\
\hline$¥ 5,000,000$ to $<¥ 8,000,000$ & $120(20.0)$ & $29(19.3)$ & $38(25.3)$ & $23(15.3)$ & $30(20.0)$ \\
\hline$¥ 8,000,000$ or more & $72(12.0)$ & $8(5.3)$ & $25(16.7)$ & $17(11.3)$ & $22(14.7)$ \\
\hline Declined to answer & $62(10.3)$ & $23(15.3)$ & $11(7.3)$ & $16(10.7)$ & $12(8.0)$ \\
\hline \multicolumn{6}{|l|}{ Living status } \\
\hline Live alone (NHWS) & $82(13.7)$ & $28(18.7)$ & $18(12.0)$ & $19(12.7)$ & $22(14.7)$ \\
\hline Live with someone (NHWS) & $518(86.3)$ & $122(81.3)$ & $132(88.0)$ & $131(87.3)$ & $128(85.3)$ \\
\hline Mean (SD) Charlson comorbidity index & $0.39(0.72)$ & $0.47(0.78)$ & $0.35(0.69)$ & $0.47(0.81)$ & $0.26(0.56)$ \\
\hline \multicolumn{6}{|l|}{ BMI } \\
\hline$<18.5$ & $39(6.5)$ & $11(7.3)$ & $6(4.0)$ & $11(7.3)$ & $11(7.3)$ \\
\hline$\geq 18.5-<23$ & $277(46.2)$ & $54(36.0)$ & $71(47.3)$ & $61(40.7)$ & $91(60.7)$ \\
\hline$\geq 23-<25$ & $137(22.8)$ & $36(24.0)$ & $40(26.7)$ & $30(20.0)$ & $31(20.7)$ \\
\hline$>25$ & $147(24.5)$ & $49(32.7)$ & $33(22.0)$ & $48(32.0)$ & $17(11.3)$ \\
\hline \multicolumn{6}{|l|}{ Parkinson's disease } \\
\hline Not experienced & $599(99.8)$ & $149(99.3)$ & $150(100)$ & $150(100)$ & $150(100)$ \\
\hline Experienced & $1(0.2)$ & $1(0.7)$ & 0 & 0 & 0 \\
\hline \multicolumn{6}{|l|}{ Falls } \\
\hline No fall in the last year & $387(64.5)$ & $80(53.3)$ & $104(69.3)$ & $83(55.3)$ & $120(80.0)$ \\
\hline Fall in the last year & $213(35.5)$ & $70(46.7)$ & $46(30.7)$ & $67(44.7)$ & $30(20.0)$ \\
\hline \multicolumn{6}{|l|}{ Smoking status } \\
\hline Never & $223(37.2)$ & $55(36.7)$ & $54(36.0)$ & $53(35.3)$ & $61(40.7)$ \\
\hline Former & $271(45.2)$ & $63(42.0)$ & $78(52.0)$ & $60(40.0)$ & $70(46.7)$ \\
\hline Current & $106(17.7)$ & $32(21.3)$ & $18(12.0)$ & $37(24.7)$ & $19(12.7)$ \\
\hline \multicolumn{6}{|l|}{ Use of alcohol } \\
\hline Abstain & $147(24.5)$ & $46(30.7)$ & $27(18.0)$ & $42(28.0)$ & $32(21.3)$ \\
\hline Currently consume & $453(75.5)$ & $104(69.3)$ & $123(82.0)$ & $108(72.0)$ & $118(78.7)$ \\
\hline \multicolumn{6}{|l|}{ Vigorous exercise in the past 30 days } \\
\hline No & $284(47.3)$ & $91(60.7)$ & $45(30.0)$ & $92(61.3)$ & $56(37.3)$ \\
\hline Yes & $316(52.7)$ & $59(39.3)$ & $105(70.0)$ & $58(38.7)$ & $94(62.7)$ \\
\hline
\end{tabular}

Abbreviations: BMI Body mass index, NHWS National Health and Wellness Survey

$\mathrm{n}(\%)$ unless noted otherwise; living status in population 2 was calculated based on the customized online survey

Our results are therefore consistent with those of others and provide evidence of an association between frailty and OAB. Although the TUGT was used in other studies assessing frailty, a systematic review confirmed that the Kihon Checklist is a reliable tool for predicting frailty. Furthermore, it is short and therefore easy to administer, assesses daily routine regardless of culture or living place, and is appropriate for use in cross-cultural studies $[15,26]$. Similarly, the OABSS is a valid tool for describing OAB symptoms [16].

It is estimated that by $206040 \%$ of the Japanese population will be aged $\geq 65$ years [27]. As frailty is considered to be a pre-disability state and potentially reversible, it is a target for both prevention and intervention to improve overall health outcomes [3]. Exercise is a key intervention for frailty [2] and may also help with symptoms of OAB through weight control 
Table 2 Logistic regression for the odds ratio between $O A B$ and frailty status, with frailty status as dependent variable

\begin{tabular}{|c|c|c|c|}
\hline Parameter & Odds ratio & $95 \% \mathrm{Cl}$ & $p$-Value \\
\hline \multicolumn{4}{|l|}{ OAB status } \\
\hline No & Reference & & $<0.001$ \\
\hline Yes & 2.776 & $2.179-3.538$ & \\
\hline Age per 1 unit & 0.981 & $0.955-1.008$ & 0.161 \\
\hline Charlson comorbidity index per 1 unit & 1.391 & $1.191-1.626$ & $<0.001$ \\
\hline \multicolumn{4}{|l|}{ Sex } \\
\hline Male & Reference & & 0.750 \\
\hline Female & 0.954 & $0.715-1.273$ & \\
\hline \multicolumn{4}{|l|}{ Level of education } \\
\hline University degree & Reference & & 0.001 \\
\hline No/declined to answer & 1.480 & $1.183-1.852$ & \\
\hline \multicolumn{4}{|l|}{ Household income } \\
\hline$<¥ 3,000,000$ & Reference & & 0.005 \\
\hline$¥ 3,000,000$ to $<¥ 5,000,000$ & 0.739 & $0.547-0.999$ & \\
\hline$¥ 5,000,000$ to $<¥ 8,000,000$ & 0.593 & $0.416-0.845$ & \\
\hline$¥ 8,000,000$ or more & 0.530 & $0.342-0.822$ & \\
\hline Declined to answer & 0.981 & $0.683-1.411$ & \\
\hline \multicolumn{4}{|l|}{ Living status (NHWS) } \\
\hline Live alone & Reference & & 0.402 \\
\hline Live with someone & 1.159 & $0.821-1.636$ & \\
\hline \multicolumn{4}{|l|}{ BMI category (Kihon checklist) } \\
\hline$<18.5$ & Reference & & $<0.001$ \\
\hline$\geq 18.5-<23$ & 0.489 & $0.329-0.724$ & \\
\hline$\geq 23-<25$ & 0.559 & $0.363-0.860$ & \\
\hline$\geq 25$ & 1.044 & $0.684-1.594$ & \\
\hline \multicolumn{4}{|l|}{ Smoking status } \\
\hline Never & Reference & & 0.012 \\
\hline Former & 1.148 & $0.868-1.518$ & \\
\hline Current & 1.604 & $1.169-2.203$ & \\
\hline \multicolumn{4}{|l|}{ Use of alcohol } \\
\hline Abstain & Reference & & 0.118 \\
\hline Currently consume alcohol & 0.822 & $0.642-1.051$ & \\
\hline \multicolumn{4}{|l|}{ Vigorous exercise in the past 30 days } \\
\hline No & Reference & & $<0.001$ \\
\hline Yes & 0.506 & $0.405-0.633$ & \\
\hline
\end{tabular}

Abbreviations: BMI Body mass index, NHWS National Health and Wellness Survey, OAB overactive bladder

[28]. In addition, a number of pharmacological treatments are available for $\mathrm{OAB}$, but data are limited on the treatment of $\mathrm{OAB}$ among the frail older population. Reasons for this include exclusion from clinical trials, the vulnerability of this population, co-morbidities, and other medications [29-31]. A better understanding of the pathophysiology of $\mathrm{OAB}$ as well as the relationship between $O A B$ and frailty will help to optimize treatment strategies for this population. OAB should potentially be considered as part of a geriatric syndrome, and many factors should be considered when determining how to manage $\mathrm{OAB}$ in the context of frailty to achieve the best outcome for an individual [29-31]. Given the anticipated rise in the older population in both Japan and worldwide [29], there will likely be an associated increase in the number of patients with $O A B$, with and without frailty. Further investigation of $\mathrm{OAB}$ and its management in the frail older population, including pharmacotherapy, is warranted, therefore $[29,30,32$, 33]. Recently, a treatment algorithm and guidelines for the management of older frail individuals with urinary 

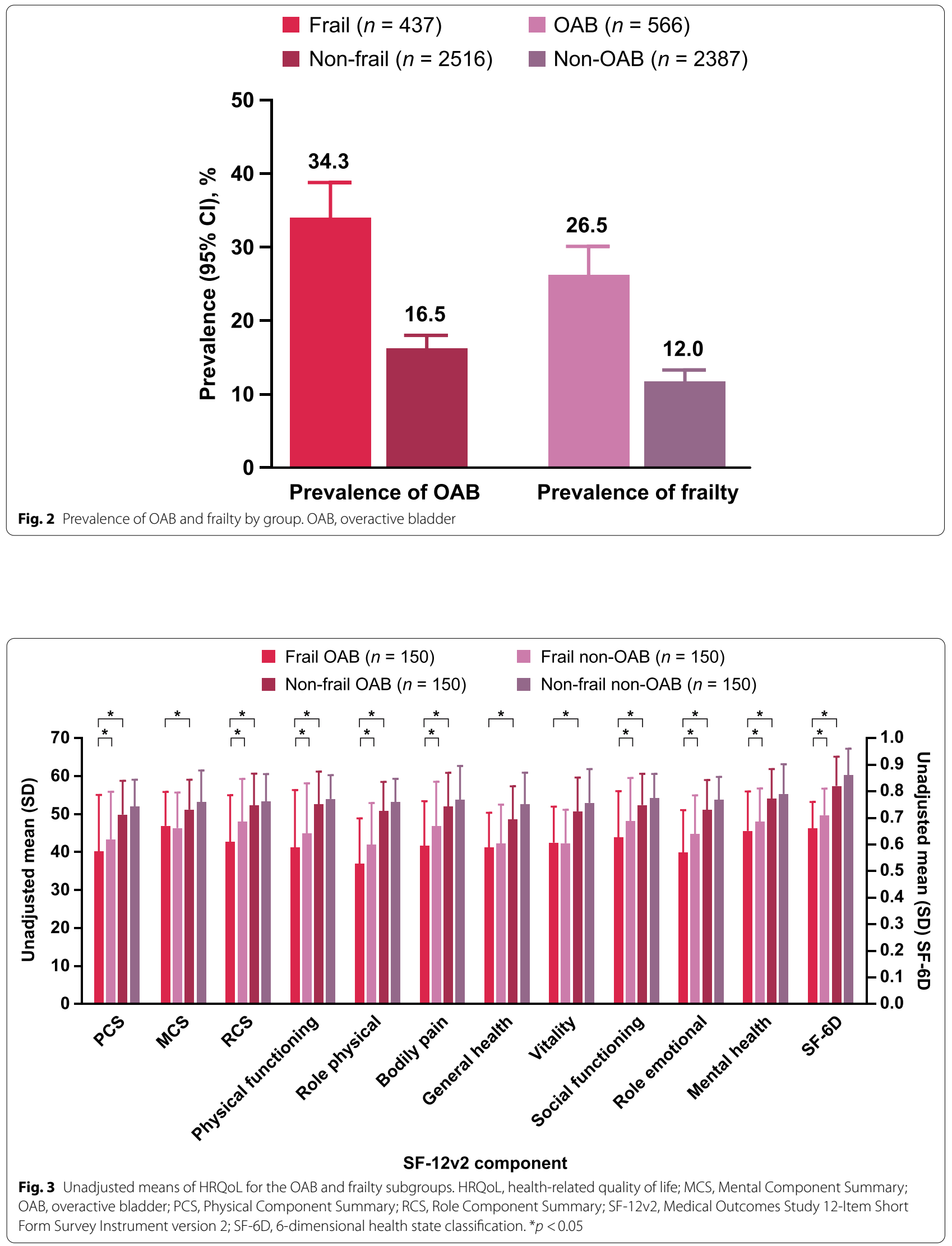


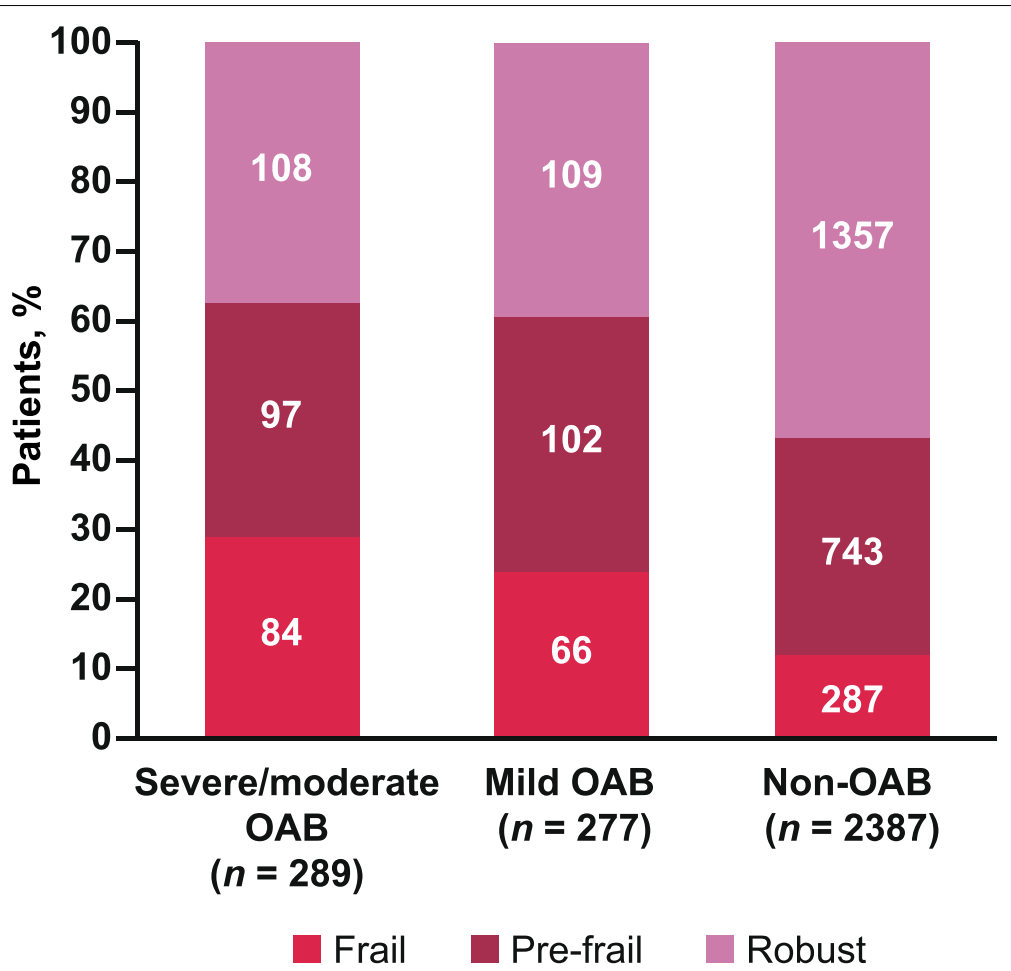

Fig. 4 Relationship between $O A B$ severity and frailty status. $O A B$, overactive bladder

incontinence have been developed by the 6th International Consultation on Incontinence [34].

Given the nature of the study, the response rate to the questionnaire and selection bias are inevitable. Participants could withdraw at any time and without reason, also potentially leading to bias. Furthermore, as data were collected via online surveys there could be a bias toward younger, more highly educated and/ or less frail individuals who are more independent and tech-savvy for completing such a survey (vs. older, less educated and/or more frail individuals who are unable to complete an online survey). In addition, as target sample sizes were imposed for each subgroup, those who were eligible and responded fastest were included. It should also be noted that the questionnaires used (Kihon Checklist, OABSS and SF-12v2) have not been validated for online use. As this is a cross-sectional survey and analysis, any causality between frailty and $\mathrm{OAB}$ cannot be assessed. Also, any medication for $\mathrm{OAB}$ taken by respondents may affect their OABSS and HRQoL scores. Finally, the SF12v2 and SF-6D were used to assess HRQoL, and it is not known how sensitive these generic measures are at detecting any potential deterioration in HRQoL in the frail and $O A B$ populations.

\section{Conclusions}

These data highlight the statistically significant positive correlation between frailty and $O A B$ among older adults in Japan and the higher prevalence of $\mathrm{OAB}$ among frail older adults, as well as of frailty among older adults with $\mathrm{OAB}$. The study may also provide valuable data on the burden of $\mathrm{OAB}$ and frailty on older adults to healthcare professionals when considering future healthcare planning.

\section{Abbreviations}

ANOVA: Analysis of variance; BMI: Body mass index; Cl: Confidence interval; HRQoL: Health-related quality of life; MCS: Mental Component Summary; MHLW: Ministry of Health, Labor and Welfare; NHWS: National Health and Wellness Survey; OAB: Overactive bladder; OABSS: Overactive bladder symptom score; PCS: Physical Component Summary; RCS: Role Component Summary; SD: Standard deviation; SF-12v2: Medical Outcomes Study 12-Item Short Form Survey Instrument version 2.

\section{Supplementary Information}

The online version contains supplementary material available at https://doi. org/10.1186/s12877-022-02756-7.

Additional file 1: Table S1. Baseline OABSS, question responses and OAB severity.

Additional file 2: Figure S1. Adjusted means of HRQoL among frail participants with and without $O A B$ 


\section{Acknowledgements}

The authors would like to thank all patients who completed the surveys. Medical writing support was provided by Becky Ayles of Excel Scientific Solutions and funded by Astellas Pharma Global Development, Inc.

\section{Authors' contributions}

All authors made a substantial contribution to the study design, and analysis and interpretation of the study data. KI, YT, and MU were responsible for the acquisition of study data. All authors contributed to the preparation of the manuscript and approved the final version for submission.

\section{Funding}

This study was funded by Astellas Pharma, Inc. Employees of the funding body were involved in the design of the study and collection, analysis, and interpretation of data, with guidance from the medical advisers (MY and SS). Feedback on the manuscript was also provided to the authors.

\section{Availability of data and materials}

Researchers may request access to anonymized participant level data, trial level data and protocols from Astellas-sponsored clinical trials at www.clini calstudydatarequest.com. For the Astellas criteria on data sharing see: https:// clinicalstudydatarequest.com/Study-Sponsors/Study-Sponsors-Astellas.aspx.

\section{Declarations}

\section{Ethics approval and consent to participate}

Approval for this study was provided by a Central IRB (Pearl IRB, Indianapolis, IN, USA). All participants provided informed consent as an inclusion criterion. This was a non-interventional study based on data from two web-based questionnaires used in Japan and was performed in accordance with the Declaration of Helsinki.

\section{Consent for publication}

\section{Not applicable.}

\section{Competing interests}

MY: Daily allowances/lecture fees from Astellas Pharma Inc., Ferring Pharmaceuticals Co., Ltd., and Kissei Pharmaceutical Co., Ltd.; manuscript fee paid by Astellas Pharma Inc., and Kissei Pharmaceutical Co., Ltd.; research funding from Astellas Pharma Inc., and Taiho Pharmaceutical Co., Ltd. SS: Nothing to disclose outside of the presented work. $\mathrm{KI}, \mathrm{YT}, \mathrm{MU}$ : Employees of Astellas Pharma Inc.

\section{Author details}

'Department of Urology, National Center for Geriatrics and Gerontology, Obu, Aichi, Japan. ${ }^{2}$ Department of Geriatric Medicine, National Center for Geriatrics and Gerontology, Obu, Aichi, Japan. ${ }^{3}$ Medical Affairs, Astellas Pharma Inc., Tokyo, Japan. ${ }^{4}$ Data Science, Development, Astellas Pharma Inc., Tokyo, Japan.

Received: 6 August 2021 Accepted: 5 January 2022

Published online: 21 January 2022

\section{References}

1. European parliamentary research service. European Parliament briefing; continental democracies. Japan's ageing society 2020. https://www. europarl.europa.eu/RegData/etudes/BRIE/2020/659419/EPRS_BRI. (2020)659419_EN.pdf. Accessed 8 June 2021.

2. Chen X, Mao G, Leng SX. Frailty syndrome: an overview. Clin Interv Aging. 2014;9:433-41.

3. Kojima G, Iliffe S, Taniguchi Y, Shimada H, Rakugi H, Walters K. Prevalence of frailty in Japan: a systematic review and meta-analysis. J Epidemiol. 2017:27:347-53.

4. Satake S, Shimada H, Yamada M, Kim H, Yoshida H, Gondo Y, et al. Prevalence of frailty among community-dwellers and outpatients in Japan as defined by the Japanese version of the cardiovascular health study criteria. Geriatr Gerontol Int. 2017;17:2629-34.

5. D'Ancona C, Haylen B, Oelke M, Abranches-Monteiro L, Arnold E, Goldman $\mathrm{H}$, et al. The international continence society (ICS) report on the terminology for adult male lower urinary tract and pelvic floor symptoms and dysfunction. Neurourol Urodyn. 2019;38:433-77.

6. Homma Y, Yamaguchi $\mathrm{O}$, Hayashi K. Neurogenic bladder society committee. An epidemiological survey of overactive bladder symptoms in Japan. BJU Int. 2005;96:1314-8.

7. Ikeda M, Nozawa K. Prevalence of overactive bladder and its related factors in Japanese patients with diabetes mellitus. Endocr J. 2015;62:847-54.

8. Coyne KS, Sexton CC, Irwin DE, Kopp ZS, Kelleher CJ, Milsom I. The impact of overactive bladder, incontinence and other lower urinary tract symptoms on quality of life, work productivity, sexuality and emotional well-being in men and women: results from the EPIC study. BJU Int. 2008;101:1388-95.

9. Milsom I, Kaplan SA, Coyne KS, Sexton CC, Kopp ZS. Effect of bothersome overactive bladder symptoms on health-related quality of life, anxiety, depression, and treatment seeking in the United States: results from EpiLUTS. Urology. 2012;80:90-6.

10. Carlson KV, Rovner ES, Nair KV, Deal AS, Kristy RM, Schermer CR. Factors associated with improvements in patient-reported outcomes during mirabegron or antimuscarinic treatment of overactive bladder syndrome: a registry study (PERSPECTIVE). Adv Ther. 2019;36:1906-21.

11. Yehoshua A, Chancellor M, Vasavada S, Malone DC, Armstrong EP, Joshi $M$, et al. Health resource utilization and cost for patients with incontinent overactive bladder treated with anticholinergics. J Manag Care Spec Pharm. 2016;22:406-13.

12. Suskind AM, Quanstrom K, Zhao S, Bridge M, Walter LC, Neuhaus J, et al. Overactive bladder is strongly associated with frailty in older individuals. Urology. 2017;106:26-31.

13. Kantar group and affiliates. National Health and wellness survey (NJWS). Patient-reported healthcare evidence 2020. https://www. kantar.com/expertise/health/da\%2D\%2D-real-world-data-prosclaims-and-health-records/national-health-and-wellness-survey-nhws. Accessed 8 June 2021.

14. QualityMetric Inc. and medical outcomes trust. SF-12 $2^{\mathrm{TM}}$ Health Survey 2002. https://sa1s3.patientpop.com/assets/docs/74113.pdf. Accessed 8 June 2021.

15. Satake S, Senda K, Hong YJ, Miura H, Endo H, Sakurai T, et al. Validity of the Kihon checklist for assessing frailty status. Geriatr Gerontol Int. 2016;16:709-15.

16. Homma Y, Yoshida M, Seki N, Yokoyama O, Kakizaki H, Gotoh M, et al. Symptom assessment tool for overactive bladder syndrome--overactive bladder symptom score. Urology. 2006;68:318-23.

17. Shiroiwa T, Fukuda T, Ikeda S, Igarashi A, Noto S, Saito S, et al. Japanese population norms for preference-based measures: EQ-5D-3L, EQ5D-5L, and SF-6D. Qual Life Res. 2016;25:707-19.

18. Fleishman JA, Selim AJ, Kazis LE. Deriving SF-12v2 physical and mental health summary scores: a comparison of different scoring algorithms. Qual Life Res. 2010;19:231-41.

19. Brazier JE, Roberts J. The estimation of a preference-based measure of health from the SF-12. Med Care. 2004;42:851-9.

20. Quan H, Li B, Couris CM, Fushimi K, Graham P, Hider P, et al. Updating and validating the Charlson comorbidity index and score for risk adjustment in hospital discharge abstracts using data from 6 countries. Am J Epidemiol. 2011;173:676-82.

21. Bennink D, Voorham JC, Putter H, Pelger RCM. Voorham van der Zalm PJ. Differences in EMG activity of the pelvic floor muscles in women with complaints of the overactive bladder syndrome and healthy women. J Womens Health Gyn. 2020;7:203.

22. Banakhar MA, Al-Shaiji TF, Hassouna MM. Pathophysiology of overactive bladder. Int Urogynecol J. 2012;23:975-82.

23. Savva GM, Donoghue OA, Horgan F, O'Regan C, Cronin H, Kenny RA. Using timed up-and-go to identify frail members of the older population. J Gerontol A Biol Sci Med Sci. 2013;68:441-6.

24. Hunter KF, Voaklander D, Hsu ZY, Moore KN. Lower urinary tract symptoms and falls risk among older women receiving home support: a prospective cohort study. BMC Geriatr. 2013;13:46.

25. Szabo SM, Gooch KL, Walker DR, Johnston KM, Wagg AS. The association between overactive bladder and falls and fractures: a systematic review. Adv Ther. 2018;35:1831-41. 
26. Sewo Sampaio PY, Sampaio RAC, Yamada M, Arai H. Systematic review of the Kihon checklist: is it a reliable assessment of frailty? Geriatr Gerontol Int. 2016;16:893-902.

27. National Institute of Population and Social Security Research (Japan). Population \& Household Projection, Population Projection for Japan: 2011-2060, II Summary of Population Trends 2012. http://www.ipss.go.jp/ site-ad/index_english/esuikei/econ2.html. Accessed 8 June 2021.

28. Wyman JF, Burgio KL, Newman DK. Practical aspects of lifestyle modifications and behavioural interventions in the treatment of overactive bladder and urgency urinary incontinence. Int J Clin Pract. 2009;63:1177-91.

29. Suskind AM. Frailty and lower urinary tract symptoms. Curr Urol Rep. 2017;18:67.

30. Wolff GF, Kuchel GA, Smith PP. Overactive bladder in the vulnerable elderly. Res Rep Urol. 2014;6:131-8.

31. Vaughan CP, Markland AD, Smith PP, Burgio KL, Kuchel GA. American Geriatrics Society/National Institute on Aging urinary incontinence conference planning committee and faculty. Report and research agenda of the American Geriatrics Society and National Institute on Aging bedside-to-bench conference on urinary incontinence in older adults: a translational research agenda for a complex geriatric syndrome. J Am Geriatr Soc. 2018;66:773-82.

32. Vouri SM, Kebodeaux CD, Stranges PM, Teshome BF. Adverse events and treatment discontinuations of antimuscarinics for the treatment of overactive bladder in older adults: a systematic review and meta-analysis. Arch Gerontol Geriatr. 2017:69:77-96.

33. Makhani A, Thake M, Gibson W. Mirabegron in the treatment of overactive bladder: safety and efficacy in the very elderly patient. Clin Interv Aging. 2020;15:575-81.

34. Gibson W, Johnson T, Kirschner-Hermanns R, Kuchel G, Markland A, Orme $S$, et al. Incontinence in frail elderly persons: report of the 6th international consultation on incontinence. Neurourol Urodyn. 2021;40:38-54.

\section{Publisher's Note}

Springer Nature remains neutral with regard to jurisdictional claims in published maps and institutional affiliations.

Ready to submit your research? Choose BMC and benefit from:

- fast, convenient online submission

- thorough peer review by experienced researchers in your field

- rapid publication on acceptance

- support for research data, including large and complex data types

- gold Open Access which fosters wider collaboration and increased citations

- maximum visibility for your research: over $100 \mathrm{M}$ website views per year

At BMC, research is always in progress.

Learn more biomedcentral.com/submissions 